Please do not remove this page

RMIT

UNIVERSITY

\title{
The equivalent translational compliance of steel or wood studs and resilient channel bars
}

Hirakawa, Susumu; Davy, John

https://researchrepository.rmit.edu.au/esploro/outputs/9921862260101341/filesAndLinks?institution=61RMIT_INST\&index=null

Hirakawa, S., \& Davy, J. (2015). The equivalent translational compliance of steel or wood studs and resilient channel bars. Journal of the Acoustical Society of America, 137(4), 1647-1657.

https://doi.org/10.1121/1.4916706

Document Version: Accepted Manuscript

Published Version: https://doi.org/10.1121/1.4916706

Repository homepage: https://researchrepository.rmit.edu.au

(c) 2015 Acoustical Society of America

Downloaded On 2023/04/26 12:27:32 +1000

Please do not remove this page 
Thank you for downloading this document from the RMIT Research Repository.

The RMIT Research Repository is an open access database showcasing the research outputs of RMIT University researchers.

RMIT Research Repository: http://researchbank.rmit.edu.au/

\section{Citation:}

Hirakawa, S and Davy, J 2015, 'The equivalent translational compliance of steel or wood studs and resilient channel bars', Journal of the Acoustical Society of America, vol. 137, no. 4, pp. 1647-1657.

See this record in the RMIT Research Repository at:

https://researchbank.rmit.edu.au/view/rmit:31149

Version: Accepted Manuscript

Copyright Statement: (C) 2015 Acoustical Society of America

Link to Published Version:

http://dx.doi.org/10.1121/1.4916706 


\title{
The equivalent translational compliance of steel studs and resilient channel bars
}

\author{
Susumu HIRAKAWA ${ }^{1}$; John Laurence DAVY² \\ ${ }_{1,2}$ RMIT University, Australia
}

\begin{abstract}
A number of recent papers have determined the compliance of steel studs for use in a model for predicting the sound insulation of cavity stud walls. Previously, the steel studs have usually been modelled as line connections. In this paper, they are also modelled as point connections where the points are the screws attaching the wall leaves to the steel studs. The compliance of the combination of resilient channel bars and wooden or steel studs, modelled as point or as line connections, is also presented. The values of compliance which make a theoretical model agree with the experimental data have been calculated. The experimental sound insulation data were measured by the National Research Council of Canada. There were 126 steel stud walls, 78 resilient channel bar and wooden stud walls, 15 resilient channel bar and steel stud walls and 4 walls with resilient channel bars on both sides of wooden studs. Linear regressions of the logarithm of the compliance against the logarithms of frequency, reduced surface density, cavity depth and number of point connections or stud spacing, were conducted in a low frequency range and in a high frequency range. The equations produced by these linear regressions can be used in sound insulation prediction models.
\end{abstract}

Keywords: Sound Insulation, Resilient mounts, Steel studs I-INCE Classification of Subjects Number: 33

\section{INTRODUCTION}

This paper presents three new models of the sound insulation of cavity stud walls with resilient channel bars and steel stud cavity walls using linear or point connection theories. Linear regressions of the logarithm of the compliance against the logarithms of frequency, the reduced surface density of the wall leaves, the cavity depth and the number of point connections or the stud spacing, were conducted in the low frequency range and in the high frequency range. The equations produced by these linear regressions can be used in sound insulation prediction models.

Poblet-Puig et al. $(1,2)$ calculated the vibrational level difference of different gypsum plaster board wall leaves which were connected via steel studs. They compared these differences with those calculated for line connections with a range of equivalent translational stiffnesses and equivalent rotational stiffnesses. Guigou-Carter and Villot (3) used this information to calculate the sound insulation at low frequencies of two gypsum plaster board steel stud cavity walls with sound absorbing material in the wall cavity. At higher frequencies they modelled the steel studs as resilient point connections situated at the positions of the screws used to attach the gypsum plaster board to the steel stud.

Poblet-Puig et al. $(1,4)$ have shown that a steel stud can be modelled as a translational spring with an equivalent translational stiffness which varies with frequency. Vigran (5) derived a best-fit third order polynomial approximation to the logarithm of Poblet-Puig's numerical values as a function of the logarithm of the frequency for the most common type of steel stud.

Davy et al. (2) derived equations for the compliance of steel studs in cavity stud walls. It should be possible to develop a similar method for predicting the sound insulation of cavity stud walls with resilient channel bars by using the same approach. The expected outcome of this research is a regression equation for predicting the compliance of resilient channel bars which can be used in existing sound insulation theories such as those of Davy 2012 (6).

S3232765@student.rmit.edu.au

2 john.davy@rmit.edu.au 


\section{Methods}

\subsection{Calculation of sound transmission factor with point and line connections}

Davy (6) derived equations for the sound transmission factor $\tau$ of a cavity wall via resilient massless point and line connections:

$$
\begin{gathered}
\tau=\frac{16 n \rho_{0}^{2} c^{4} Q R}{\pi^{5} f^{2}\left[\left(m_{1} f_{c 2}+m_{2} f_{c 1}\right)^{2}+64 f^{2} m_{1}^{2} m_{2}^{2} c^{4} C^{2}\right]} \quad \text { (Point connection) } \\
\tau=\frac{8 \rho_{0}^{2} c^{3} Q R}{\left[g^{2}+\left(8 \pi f^{\frac{3}{2}} m_{1} m_{2} c C-g\right)^{2}\right] b \pi^{3} f^{2}} \quad \text { (Line connection) }
\end{gathered}
$$

$f$ is the frequency, $n$ is the number of point connections per unit area calculated from the stud spacing and the resilient channel bar or screw spacing, $b$ is the distance between the line connections, in other words, the stud spacing. $\rho_{0}$ is the density of air $\left[1.18 \mathrm{~kg} / \mathrm{m}^{3}\right], c$ is the speed of sound in the air [343 m/s], $m_{i}$ is the mass per unit area of the $i$ th gypsum wall leaf obtained from the data, $f_{c i}$ is the critical frequency of the $i$ th wall leaf, and $C$ is the compliance of the connection. In the case of a line connection, $C$ has the dimensions of length/(force/length) $=1 /$ pressure. For point connection, $C$ has dimensions of length/force.

$Q$ is

$$
\mathrm{Q}= \begin{cases}1+e & \text { if } f<f_{c 1} \\ e & \text { if } f \geq f_{c 1}\end{cases}
$$

$e$ is

$$
\mathrm{e}=\frac{\pi f_{c 1} \sigma_{1}}{4 f \eta_{1}}
$$

$e$ is the ratio of the resonant vibrational energy of the first wall to its mass law vibrational energy Cremer, Heckl (7), $\sigma_{i}$ is the radiation efficiency and $\eta_{i}$ is the total damping loss factor of the $i$ th wall leaf. The condition for $Q$ needs to be stated because at and the above the critical frequency, it is not possible to distinguish between the forced response given by the mass law response below the critical frequency, and the resonant response.

$R$ is calculated by using following equation:

$$
R=\left\{\begin{array}{lll}
1+r & \text { if } & f<f_{c 2} \\
r & \text { if } f \geq f_{c 2}
\end{array}\right.
$$

$r$ is calculated as the ratio of the power radiated by the resonant velocity of the second leaf and the power radiated by the vibrational near field in the second wall leaf generated by the connection.

$$
\begin{array}{ll}
r=\frac{\pi f_{c 2} \sigma_{2}}{4 f \eta_{2}} & \text { (Point connection) } \\
r=\frac{\sigma_{2}}{2 \eta_{2}} \sqrt{\frac{f_{c 2}}{f}} \quad \text { (Line connection) }
\end{array}
$$

The value of $r$ is dependent on the connection type and because of this fact, the value of $R$ also depends on the type of connection.

Because the line connection equation is non-symmetrical, the wall leaves need to be numbered so that $f_{c l}<f_{c 2}$. This is because total internal reflection will occur for some propagation directions if the wall leaves are numbered in the opposite order.

$g$ is calculated by

$$
g=m_{1} \sqrt{f_{c 2}}+m_{2} \sqrt{f_{c 1}}
$$


The equations (1) and (2) can be simplified to the following equations when the properties of the two walls are the same.

$$
\begin{gathered}
\tau=\frac{4 n \rho_{0}^{2} c^{4} Q}{\pi f^{2} m^{2}\left[f_{c}^{2}+16 f^{2} m^{2} c^{4} C^{2}\right]} \quad \text { (Point connection) } \\
\tau=\frac{2 \rho_{0}^{2} c^{3} Q R}{\left[f_{c}+\left(4 \pi f^{\frac{3}{2}} m c C-\sqrt{f_{c}}\right)^{2}\right] b \pi^{3} m^{2} f^{2}} \quad \text { (Line connection) }
\end{gathered}
$$

The equation (1) and (2) will be combined with the theory for airborne sound transmission across the cavity (8). The values of the compliance $C$ which make the values of the predicted sound transmission values agree with the measured values of sound transmission will be determined. Formulae for the compliance will be obtained using regression analysis.

\subsection{Compliance Calculations of line and point connections}

The theoretical equivalent translational compliances obtained by Davy (6) were calculated by trial and error. For this project, the equations have been inverted and the compliance is automatically calculated. The equations for calculating the equivalent translational compliance are;

$$
\begin{gathered}
\tau_{s}=\tau_{t}-\tau_{a} \\
\tau_{\mathrm{t}}=10^{\frac{R_{t}}{10}} \\
\tau_{\mathrm{a}}=10^{\frac{R_{a}}{10}}
\end{gathered}
$$

where $\tau_{s}$ is the structure borne transmission coefficient, $\tau_{t}$ is the total transmission coefficient given by the experimental data, $\tau_{a}$ is the calculated theoretical air borne transmission coefficient, $R_{t}$ is the measured total sound reduction index and $R_{a}$ is calculated air borne sound reduction index. Thus, the calculation for the compliance is

$$
\begin{gathered}
\mathrm{C}_{M}=\sqrt{\frac{\left(16 n \rho_{0}^{2} c^{4} Q R\right) / \pi^{5} f^{2} \tau_{s}-\left(m_{1} f_{c 2}+m_{2} f_{c 1}\right)^{2}}{64 f^{2} m_{1}^{2} m_{2}^{2} c^{4}}} \quad \text { (Point connection) } \\
\mathrm{C}_{M}=\frac{\sqrt{8 c^{3} \rho_{0}^{2} Q R / \pi^{3} \tau_{s} b f^{2}-g^{2}}+g}{8 \pi c f^{\frac{3}{2}} m_{1} m_{2}} \quad \text { (Line connection) }
\end{gathered}
$$

These inverted equations do not always return a value. This occurs in two situations. The first occurs when sound transmission via the air in the wall cavity is higher than the total experimental value. The second is when the sum of the theoretical sound transmission via the air in the cavity and via rigid structural connections is lower than the experimental value. In the first case, the best agreement with experiment is obtained by setting the theoretical compliance to the infinity. Similarly in the second case, the best agreement with experiment is obtained by setting the theoretical compliance to zero. In both of these cases the inverted formula returns an error because it is trying to take the square root of a negative number and the compliance must be a real non-negative number. Thus, an IF function test has been used in the spreadsheet in order to eliminate these errors.

\subsection{Parameter calculation}

The sound insulation measurements analyzed in this paper were measured by the National Research Council of Canada (NRCC) (9). Davy (6) assumed that the volume density and Young's modulus of the gypsum plaster board were a generic constants. This paper used the actual surface densities of the different gypsum plaster boards. The measured Young's moduli for each type of gypsum plaster board were used (Table 1).

The density $\rho_{i}$ is given by 


$$
\rho_{i}=\frac{m_{i}}{d_{i}}
$$

$m_{i}$ and $d_{i}$ are the surface density and thickness of the gypsum plasterboard.

Table 1 - Types of gypsum plasterboard used by NRCC and their Young's moduli.

\begin{tabular}{cc}
\hline Nominal Type $(\mathrm{mm})$ & Young's Modulus average $(\mathrm{GPa})$ \\
\hline AX (16) & 2.40 \\
BX (16) & 2.18 \\
CX (16) & 2.26 \\
A (13) & 1.70 \\
B (13) & 1.86 \\
Light weight - LB (13) & 1.60 \\
\hline
\end{tabular}

The in situ damping loss factor of gypsum plaster board is assumed to be 0.03 . The in situ damping loss factor has a significant effect on the theory for airborne sound transmission across the cavity above the critical frequency, but only has a small effect below the critical frequency. The Young's moduli were calculated from measurements of flexural stiffness.

\subsection{Equation of best fit}

The theoretical predicting equation was assumed to be a function of the frequency $f$, the numbers of point connections per unit area $n$ or the stud spacing $b$, and reduced surface density $m_{r}$. The regression was taken over the low frequency range $(50-400 \mathrm{~Hz})$ and high the frequency range $(400-6300 \mathrm{~Hz}) \mathrm{on}$ each of four different measurement data sets.

Using each side of the equation of best fit as the argument of the exponential function produces the following equations.

$$
\begin{array}{cl}
C_{M}=A f^{x_{f}} m_{i}^{x_{m}} b^{x_{b}} & \text { (Line connection) } \\
C_{M}=A f^{x_{f}} m_{i}^{x_{m}} n^{x_{n}} & \text { (Point connection) }
\end{array}
$$

$A$ is the constant, $f$ is the frequency, $m_{r}$ is the reduced surface density, $b$ is the distance between the line connections, in other words, the stud spacing, $n$ is the number of point connections per unit area calculated by the stud spacing and resilient channel bar or screw spacing. The regressions of equivalent translational compliance produced the constants in the equation and their $95 \%$ confidence limits.

The reduced surface density can be calculated from the following equation.

$$
m_{i}=\frac{m_{1} m_{2}}{m_{1}+m_{2}}
$$

$m_{i}$ is the mass per unit area of the $i$ th gypsum wall leaf. The variable $m_{r}$ is used because it is how the the two surface densities are combined in the equation used to calculate normal incidence the mass-air mass resonant frequency of the cavity wall.

\section{Best fitting to compliance values}

The results obtained from the preliminary analysis of the line of best fit are shown in this section. There are 16 tables all together; two different connection models, four different combinations of the studs and/or resilient connections, and two different frequency ranges. The values of the constants and the $95 \%$ upper and lower confidence limits of the equivalent translational compliances are shown in the tables. $A$ is statistically different from one. $x_{f}, x_{m}$ and $x_{b}$ are only shown in these tables when they are statistically different from zero.

There is only one table where the line of best fit has a statistically significant dependence on the number of point connections per unit area $n$. This occurs in the low frequency range for the point connection model of wood studs with resilient channel bars on only one side. No tables showed a statistically significant dependence on the stud spacing $b$. This is probably because there were only two different stud spacing of 0.406 and $0.61(\mathrm{~m})$. The previous analysis of the Davy et al. (2), in the low frequency range for the line connection model of the steel stud only case, showed no statistically significant dependence on the frequency. The analysis presented in this paper shows statistically 
significant dependence on frequency in the low frequency range for half of the cases.

In 9 out of the 16 tables, the equivalent translational compliance is statistically significantly dependent on the reduced surface density of the gypsum plaster boards.

\subsection{Steel stud with resilient channel bar}

\subsubsection{Line Connection}

Table 2 - Values and confidence limits for the constants in the low frequency range.

$\begin{array}{cccc}\text { Constant } & \text { Value } & 95 \% \text { Upper Limit } & 95 \% \text { Lower Limit } \\ \text { A } & 5.40 \times 10^{-6} & 6.50 \times 10^{-6} & 4.30 \times 10^{-6}\end{array}$

Table 3 - Values and confidence limits for the constants in the high frequency range.

\begin{tabular}{|c|c|c|c|}
\hline Constant & Value & 95\% Upper Limit & 95\% Lower Limit \\
\hline $\mathrm{A}$ & 2.15 & 4.44 & 1.04 \\
\hline $\mathrm{x}_{\mathrm{f}}$ & -1.89 & -1.82 & -1.96 \\
\hline $\mathrm{x}_{\mathrm{m}}$ & -0.98 & -0.74 & -1.22 \\
\hline
\end{tabular}

\subsubsection{Point Connection}

Table 4 - Values and confidence limits for the constants in the low frequency range.

$\begin{array}{cccc}\text { Constant } & \text { Value } & 95 \% \text { Upper Limit } & 95 \% \text { Lower Limit } \\ \mathrm{A} & 8.18 \times 10^{-6} & 1.01 \times 10^{-5} & 6.22 \times 10^{-6}\end{array}$

Table 5 - Values and confidence limits for the constants in the high frequency range.

\begin{tabular}{cccc}
\hline Constant & Value & $95 \%$ Upper Limit & $95 \%$ Lower Limit \\
\hline $\mathrm{A}$ & 0.64 & 1.40 & 0.29 \\
$\mathrm{X}_{\mathrm{f}}$ & -1.54 & -1.46 & -1.61 \\
$\mathrm{X}_{\mathrm{m}}$ & -0.95 & -0.69 & -1.21 \\
\hline
\end{tabular}

\subsection{Wood stud with resilient channel bar}

\subsubsection{Line Connection}

Table 6 - Values and confidence limits for the constants in the low frequency range.

\begin{tabular}{cccc}
\hline Constant & Value & $95 \%$ Upper Limit & $95 \%$ Lower Limit \\
\hline $\mathrm{A}$ & $2.01 \times 10^{-4}$ & $3.58 \times 10^{-4}$ & $1.13 \times 10^{-4}$ \\
$\mathrm{X}_{\mathrm{f}}$ & -0.48 & -0.38 & -0.58 \\
$\mathrm{X}_{\mathrm{m}}$ & -0.98 & -0.76 & -1.21 \\
\hline
\end{tabular}

Table 7 - Values and confidence limits for the constants in the high frequency range.

\begin{tabular}{cccc}
\hline Constant & Value & $95 \%$ Upper Limit & $95 \%$ Lower Limit \\
\hline $\mathrm{A}$ & 0.22 & 0.31 & 0.15 \\
$\mathrm{X}_{\mathrm{f}}$ & -1.54 & -1.50 & -1.57 \\
$\mathrm{X}_{\mathrm{m}}$ & -1.16 & -1.03 & -1.28 \\
\hline
\end{tabular}

\subsubsection{Point Connection}

Table 8 - Values and confidence limits for the constants in the low frequency range.

\begin{tabular}{cccc}
\hline Constant & Value & $95 \%$ Upper Limit & $95 \%$ Lower Limit \\
\hline $\mathrm{A}$ & $5.27 \times 10^{-4}$ & $1.69 \times 10^{-3}$ & $1.65 \times 10^{-4}$ \\
$\mathrm{X}_{\mathrm{f}}$ & -0.22 & -0.06 & -0.38 \\
$\mathrm{X}_{\mathrm{m}}$ & -1.19 & -0.80 & -1.58 \\
$\mathrm{X}_{\mathrm{n}}$ & -0.87 & -0.36 & -1.38 \\
\hline
\end{tabular}

Table 9 - Values and confidence limits for the constants in the high frequency range.

\begin{tabular}{|c|c|c|c|}
\hline Constant & Value & 95\% Upper Limit & 95\% Lower Limit \\
\hline A & 0.06 & 0.09 & 0.04 \\
\hline $\mathrm{X}_{\mathrm{f}}$ & -1.16 & -1.12 & -1.20 \\
\hline $\mathrm{X}_{\mathrm{m}}$ & -1.17 & -1.04 & -1.29 \\
\hline
\end{tabular}




\subsection{Resilient channel bars on the both sides of the wall studs}

\subsubsection{Line Connection}

Table 10 - Values and confidence limits for the constants in the low frequency range.

\begin{tabular}{cccc}
\hline Constant & Value & $95 \%$ Upper Limit & $95 \%$ Lower Limit \\
\hline $\mathrm{A}$ & $1.09 \times 10^{-5}$ & $1.95 \times 10^{-5}$ & $2.33 \times 10^{-6}$ \\
\hline
\end{tabular}

Table 11 - Values and confidence limits for the constants in the high frequency range.

\begin{tabular}{cccc}
\hline Constant & Value & $95 \%$ Upper Limit & $95 \%$ Lower Limit \\
\hline $\mathrm{A}$ & $9.05 \times 10^{-3}$ & 0.17 & $4.7 \times 10^{-4}$ \\
$\mathrm{x}_{\mathrm{f}}$ & -1.25 & -0.87 & -1.64 \\
\hline
\end{tabular}

\subsubsection{Point Connection}

Table 12. Values and confidence limits for the constants in the low frequency range.

\begin{tabular}{cccc} 
Constant & Value & $95 \%$ Upper Limit & $95 \%$ Lower Limit \\
A & $1.79 \times 10^{-5}$ & $3.31 \times 10^{-5}$ & $2.79 \times 10^{-6}$ \\
\hline
\end{tabular}

Table 13 - Values and confidence limits for the constants in the high frequency range

\begin{tabular}{cccc}
\hline Constant & Value & $95 \%$ Upper Limit & $95 \%$ Lower Limit \\
\hline $\mathrm{A}$ & $2.56 \times 10^{-3}$ & $4.78 \times 10^{-2}$ & $1.37 \times 10^{-4}$ \\
$\mathrm{x}_{\mathrm{f}}$ & -0.88 & -0.49 & -1.26 \\
\hline
\end{tabular}

\subsection{Steel stud only}

\subsubsection{Line Connection}

Table 14 - Values and confidence limits for the constants in the low frequency range.

\begin{tabular}{cccc}
\hline Constant & Value & $95 \%$ Upper Limit & $95 \%$ Lower Limit \\
\hline $\mathrm{A}$ & $3.22 \times 10^{-4}$ & $4.71 \times 10^{-4}$ & $1.74 \times 10^{-4}$ \\
$\mathrm{X}_{\mathrm{f}}$ & -0.55 & -0.46 & -0.64 \\
$\mathrm{X}_{\mathrm{m}}$ & -1.07 & -0.89 & -1.26 \\
\hline
\end{tabular}

Table 15 - Values and confidence limits for the constants in the high frequency range

\begin{tabular}{cccc}
\hline Constant & Value & $95 \%$ Upper Limit & $95 \%$ Lower Limit \\
\hline $\mathrm{A}$ & 2.60 & 3.45 & 1.97 \\
$\mathrm{X}_{\mathrm{f}}$ & -1.90 & -1.87 & -1.93 \\
$\mathrm{X}_{\mathrm{m}}$ & -1.29 & -1.21 & -1.37 \\
\hline
\end{tabular}

\subsubsection{Point connection}

Table 14 - Values and confidence limits for the constants in the low frequency range.

\begin{tabular}{cccc}
\hline Constant & Value & $95 \%$ Upper Limit & $95 \%$ Lower Limit \\
\hline $\mathrm{A}$ & $1.88 \times 10^{-4}$ & $3.21 \times 10^{-4}$ & $5.55 \times 10^{-4}$ \\
$\mathrm{X}_{\mathrm{f}}$ & -0.29 & -0.15 & -0.42 \\
$\mathrm{X}_{\mathrm{m}}$ & -1.02 & -0.72 & -1.31 \\
\hline
\end{tabular}

Table 15 - Values and confidence limits for the constants in the high frequency range

$\begin{array}{cccc}\text { Constant } & \text { Value } & 95 \% \text { Upper Limit } & 95 \% \text { Lower Limit } \\ \mathrm{A} & 0.07 & 0.09 & 0.05 \\ \mathrm{x}_{\mathrm{f}} & -1.50 & -1.46 & -1.54\end{array}$




\subsection{Comparison with previous study}

Davy et al.(2) compared their best fit equations with Vigran (5) and with Poblet-Puig et al. (4) for the line connection model for $70 \mathrm{~mm}$ wide TC steel studs spaced at $600 \mathrm{~mm}$ with $13 \mathrm{~mm}$ gypsum plaster board on each side. These results are compared with this paper's equations for the steel stud only line connection model. The equation of the Vigran (5), which is a best fit third order polynomial approximation to Poblet-Puig et al.'s (4) numerically calculated equivalent translational compliance data for TC steel studs, is as follows where $x=\log _{10}(f)$;

$$
-\log _{10} C=0.6286 x^{3}-4.4051 x^{2}+10.3323 x-7.0722
$$

Davy's equations are following:

$$
\begin{gathered}
C=9.3 \times 10^{-5}\left(m_{i}^{-1.09}\right)\left(d^{0.80}\right) \quad(\text { Low frequency }) \\
C=1.74\left(f^{-1.81}\right)\left(m_{i}^{-1.81}\right)\left(b^{-1.40}\right)\left(d^{0.28}\right) \quad(\text { High frequency })
\end{gathered}
$$

Figure 1 shows the comparison of the best fit equations of these previous studies and this paper.

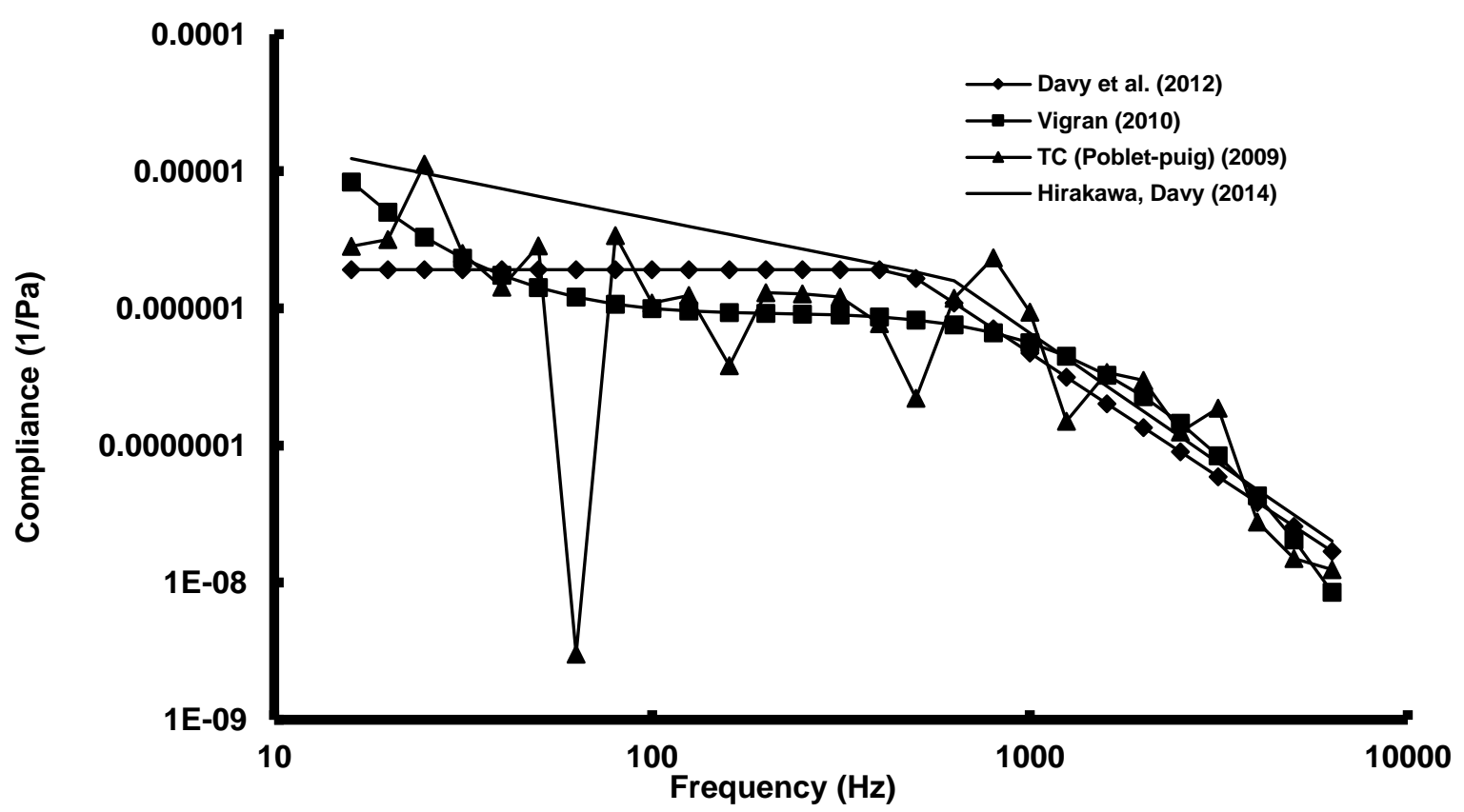

Figure 1 - Comparison of the best fit equations of this paper, Davy et al. (2) and Vigran (5) for the equivalent translational compliance with the Poblet-Puig et al. (4) data for $70 \mathrm{~mm}$ wide TC steel studs spaced at $600 \mathrm{~mm}$ with $13 \mathrm{~mm}$ gypsum plasterboard on each side.

It can be seen from figure 1, that at the lowest frequency of $16 \mathrm{~Hz}$, the compliance of $1.23 \times 10^{-5}$ (1/Pa) obtained by the present study is close to the Vigran's (5) equation but far from the other two results. At around $25 \mathrm{~Hz}$, this paper's equation is close to the numerical result of Poblet-Puig et al. (4), and slowly drops to the value of $2.09 \times 10^{-6}(1 / \mathrm{Pa})$ at $400 \mathrm{~Hz}$, where it is close to the value of compliance of $1.92 \times 10^{-6}(1 / \mathrm{Pa})$ given by the equations of Davy et al. (2). In the high frequency range the equations derived in this paper agree well with those of Davy et al. (2), Vigran (5) and Poblet-Puig et al. (4).

\subsection{COMPARISON WITH EMPIRICAL DATA}

The line of best fit for the line connection model of the steel stud only case shows good agreement with the previous studies. The lines of best fit for the point connections and for the resilient connections have not been previously studied. Thus, these equations need to be assessed with NRCC's experimental results. The values of the line of best fit equations are obtained by using the constant values given in the tables in the section 3.1 to 3.4. Since the point connection models of the resilient connections are more physically realistic, the line connection results are not presented because of 
space restrictions.

The figures 2 to 5 present the maximum, average, minimum and standard deviation of the differences between theory and the NRCC's experimental data.

It should be noted that figure 5 , the point connection method with the steel stud only combinations, shows a minimum of $-11.9 \mathrm{~dB}$. This is much lower than the other three difference calculations of the sound reduction index. Thus, the vertical axis is extended. The maximum and minimum values clearly showing the effects of the mass air mass resonance of $63 \mathrm{~Hz}$, the first resilient effects around $250 \mathrm{~Hz}$ and the critical frequency affect around $2500 \mathrm{~Hz}$. It can be seen from figure 4, that the case of resilient channel bars on both sides of the studs gives the lowest difference between the prediction model and the experimental results of the four tables. The average standard deviations shown in the figure 2 and 4 are around 1.4 and $1.5 \mathrm{~dB}$ respectively, while figure 3 gives $2 \mathrm{~dB}$ and figure 5 gives $2.85 \mathrm{~dB}$.

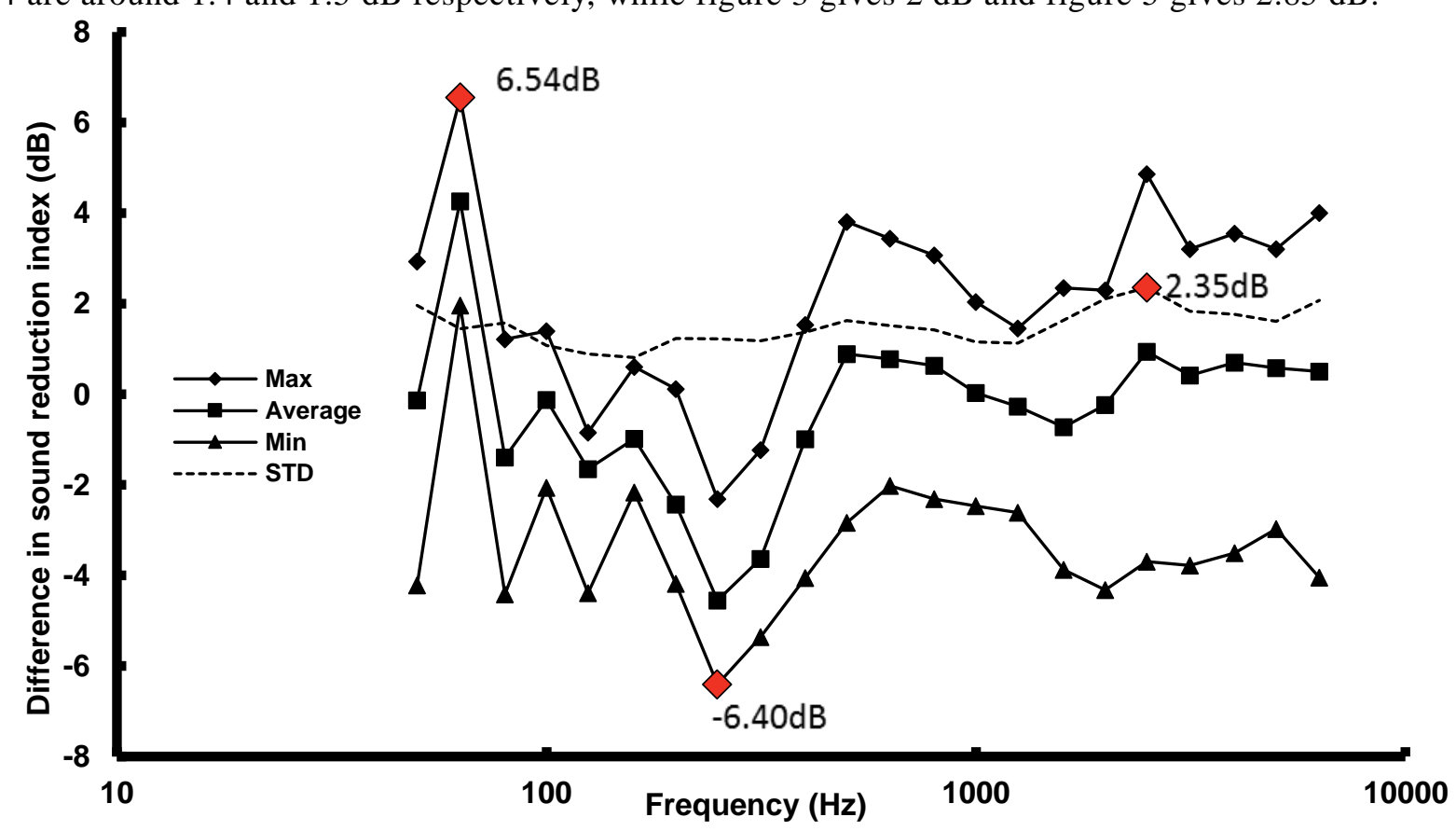

Figure 2 - Steel stud with resilient channel bars, point connection

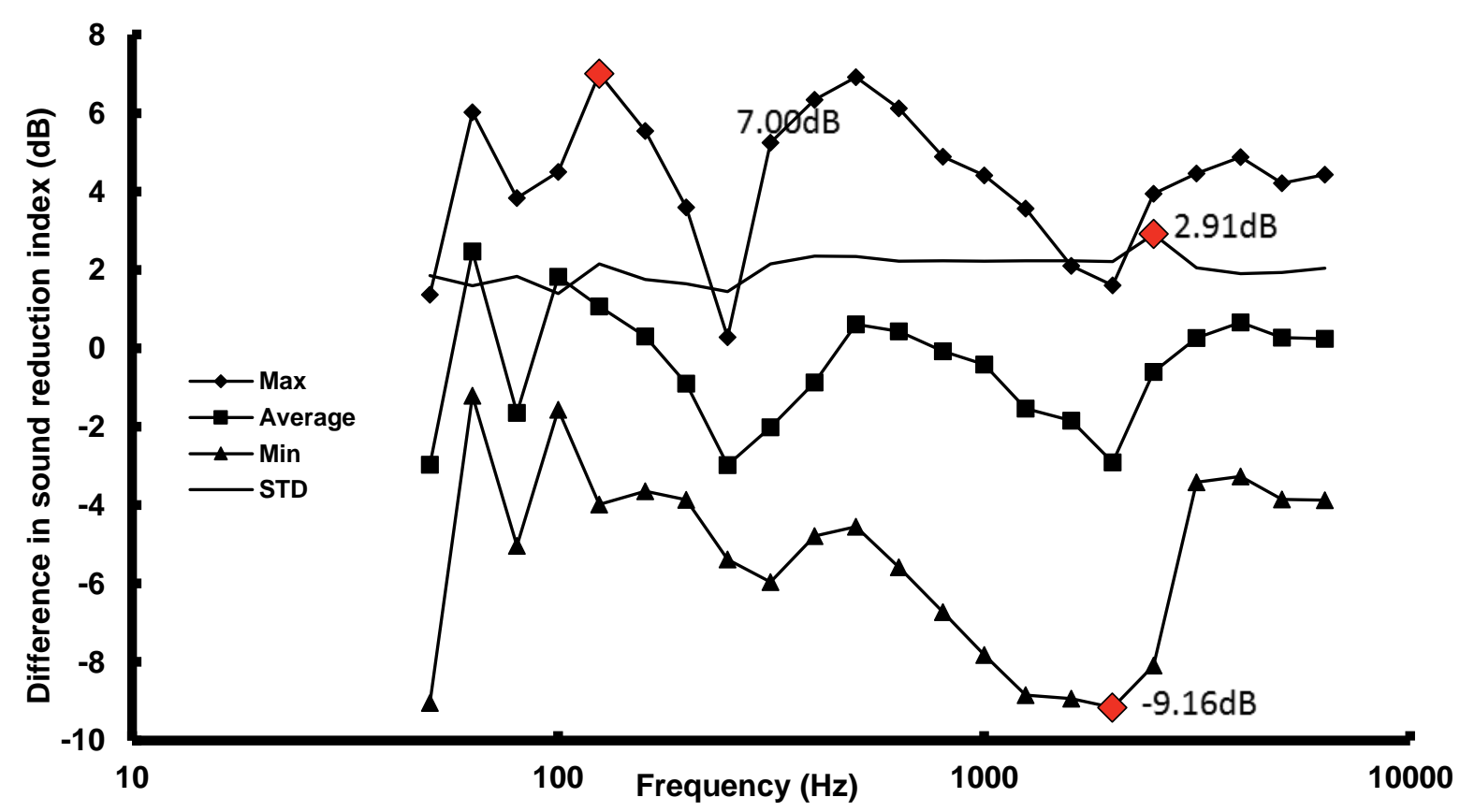

Figure 3 - Wood stud with resilient channel bars, point connection 


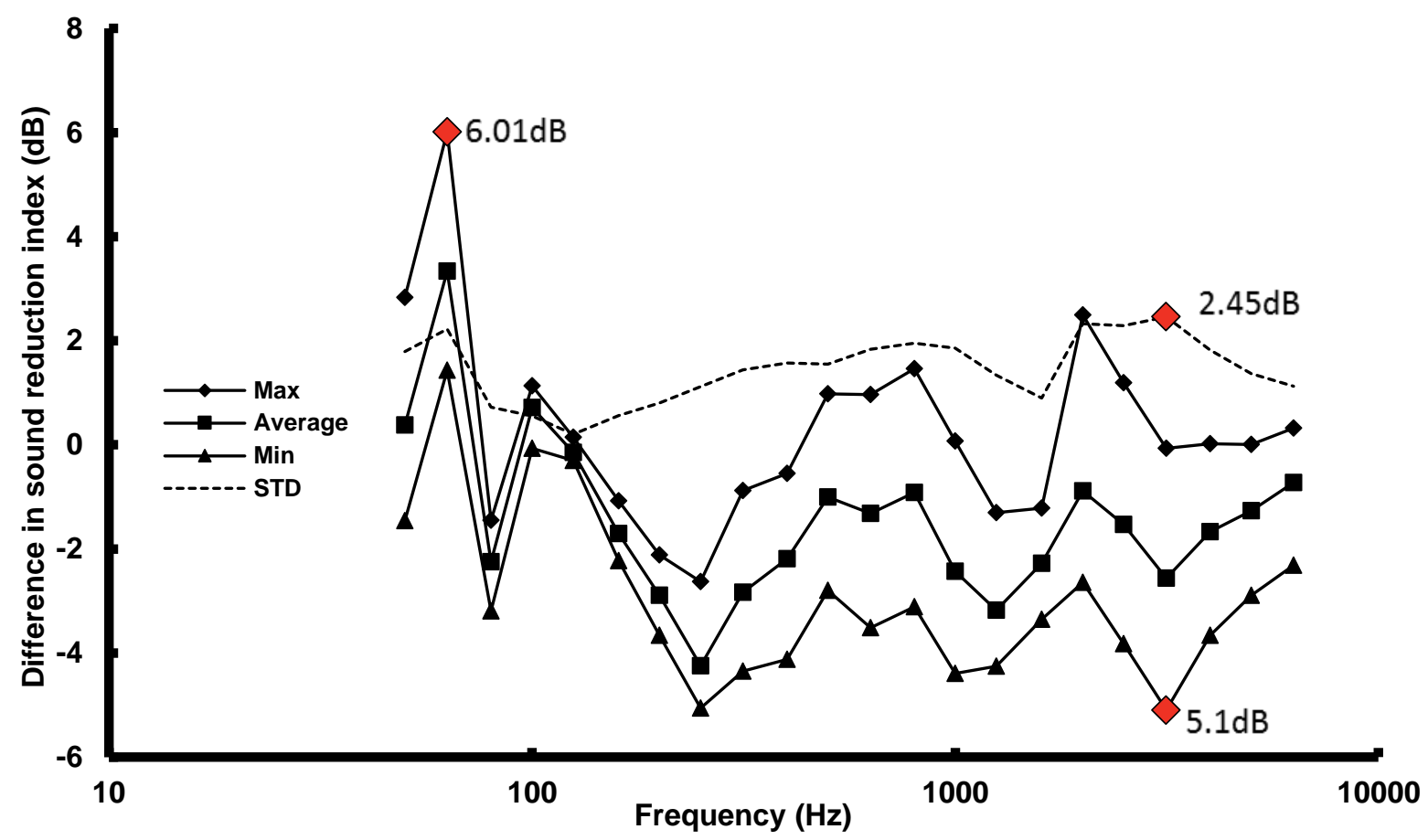

Figure 4 - Resilient channel bars on the both sides, point connection

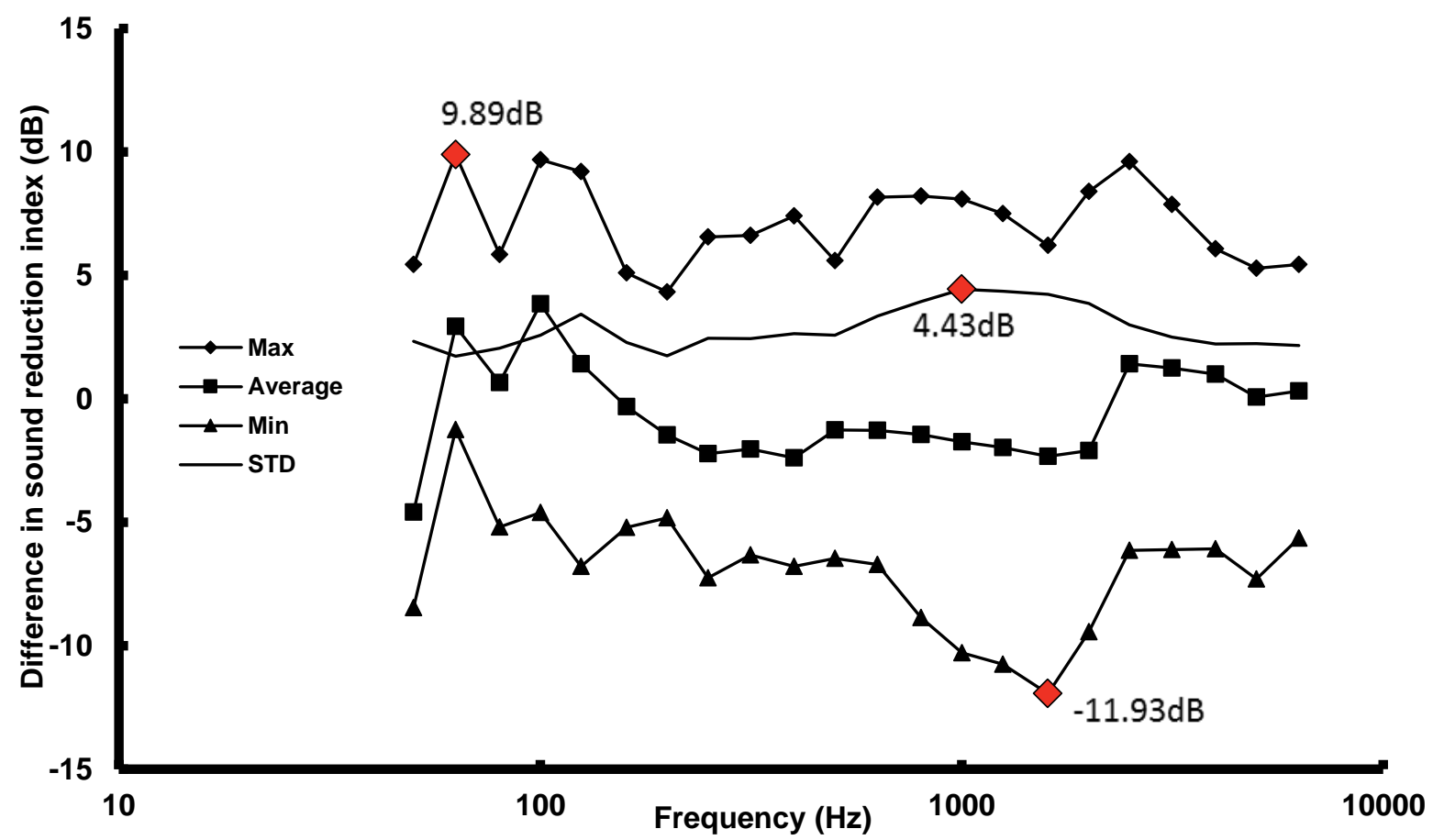

Figure 5 - Steel stud only, point connection

\section{CONCLUSIONS}

This paper has derived empirical equations for predicting the compliance using line and point connection models for four different combinations of studs and resilient channel bars. The results of the steel stud only case using the line connection model were compared with the previous predictions made by Vigran (5), Poblet-Puig et al. (4) and Davy et al.(2). There was good agreement in the high frequency range with all three previous results, and also in the low frequency range with Vigran (5) and Poblet-Puig et al. (4). These results can be used in simple theoretical models for predicting the sound insulation of gypsum plaster board cavity walls with resilient structural connections between 
their wall leaves. The differences between the theoretical predictions of the sound insulation of cavity stud walls using the point connection model and NRCC's experimental values were presented in the figures showing the maximum, minimum, average and standard deviation of the differences. The values of the standard deviation of the differences are of the order of $2 \mathrm{~dB}$ for the all resilient channel bar combinations presented. The equations presented in this paper cover a wider range of resilient connections than those of Davy et al.'s paper (2) which only considered the line connection model for steel stud only case. These new prediction equations need further verification using with experimental sound insulation data which is not part of the data set used to derive the compliances.

\section{REFERENCES}

1. Poblet-Puig J, Rodriguez-Ferran A, Guigou-Carter C, Villot M. Experimental and numerical characterization of metallic studs. Euronoise 2006; Tampere, Finland: The Acoustical Society of Finland and VTT; 2006. p. pp. 1-6.

2. Davy JL, Guigou-Carter C, Villot M. An empirical model for the equivalent translational compliance of steel studs. Journal of the Acoustical Society of America. 2012;131(6):pp. 4615-24.

3. Guigou-Carter C, Villot M. Analytical and experimental study of single frame double wall. Euronoise 2006; Tampere, Finland. Euronoise 2006,The Acoustical Society of Finland and VTT, Tampere,

Finland: The Acoustical Society of Finland and VTT; 2006. p. 1-6.

4. Poblet-Puig J, Rodriguez-Ferran A, Guigou-Carter C, Villot M. The role of studs in the sound transmission of double walls. Acta Acustica united with Acustica. 2009;95(3):pp. 555-67.

5. Vigran T. Sound insulation of double-leaf walls-Allowing for studs of finite stiffness in a transfer matrix scheme. Applied Acoustics. 2010;71(7):pp. 616-21.

6. Davy JL. Sound transmission of cavity walls due to structure borne transmission via point and line connections. Journal of the Acoustical Society of America. 2012;132(2):pp. 814-21.

7. Cremer L, Heckl M, Petersson BAT. Section 7.8.5 transmission loss in the vicinity of the critical frequency. Structure-Borne Sound-Structural Vibrations and Sound Radiation at Audio Frequencies. 3rd ed: Springer-Verlag, Berlin; 2005. p. 524-5.

8. Davy JL. The improvement of a simple theoretical model for the prediction of the sound insulation of double leaf walls. Journal of the Acoustical Society of America. 2009;127(2):841-9.

9. Halliwell RE, Nightingale TRT, Warnock ACC, Birta JA. Gypsum board walls : transmission loss data. Ottawa, Canada: Institute for Research in Construction, National Research Council of Canada, 1998. 